\title{
Force-velocity characteristics and maximal anaerobic power in male recreational marathon runners
}

Nikolaidis, Pantelis Theodoros ; Knechtle, Beat

\begin{abstract}
The aim of the present study was to examine the relationship of force-velocity (F-v) characteristics with age and race time in marathon runners. One hundred thirty-five male marathon runners (age $44.2 \pm 8.8$ years, height $176 \pm 6 \mathrm{~cm}$, body mass $24.7 \pm 2.6 \mathrm{~kg} . \mathrm{m}$ and personal record 4:02 \pm 0:45 h:min), separated into eight age groups (<30, 30-35, ., 55-60, >60 years), performed an F-v test on a cycle ergometer consisted of four $7 \mathrm{~s}$ sprints. The older age groups had the lowest scores in maximal pedalling velocity ( $v ; p<0.001, \eta=0.244)$, relative ( $r P \max$; $\mathrm{p}=0.001, \eta=0.176)$ and absolute maximal power $(\operatorname{Pmax} ; \mathrm{p}=0.009, \eta=0.135)$, whereas no difference in maximal force $(F ; p=0.558, \eta=0.044)$ was shown. Race time correlated moderately with $F(r=0.31, p<0.001)$ and Pmax $(\mathrm{r}=0.30, \mathrm{p}=0.001)$. The small magnitude of age-related differences in anaerobic power among most age groups indicated that humans without muscle strength/power training might maintain anaerobic power indices till their sixties.
\end{abstract}

DOI: https://doi.org/10.1080/15438627.2019.1608993

Posted at the Zurich Open Repository and Archive, University of Zurich

ZORA URL: https://doi.org/10.5167/uzh-171212

Journal Article

Accepted Version

Originally published at:

Nikolaidis, Pantelis Theodoros; Knechtle, Beat (2020). Force-velocity characteristics and maximal anaerobic power in male recreational marathon runners. Research in Sports Medicine, 28(1):99-110.

DOI: https://doi.org/10.1080/15438627.2019.1608993 


\title{
Force-velocity characteristics and maximal anaerobic power in male recreational marathon runners
}

\author{
Running head: Maximal anaerobic power in marathon running
}

Pantelis Theodoros Nikolaidis ${ }^{1,2}$, Beat Knechtle ${ }^{3,4}$

\author{
${ }^{1}$ Exercise Physiology Laboratory, Nikaia, Greece \\ ${ }^{2}$ Laboratory of Exercise Testing, Hellenic Air Force Academy, Acharnes, Greece \\ ${ }^{3}$ Gesundheitszentrum St. Gallen, St. Gallen, Switzerland \\ ${ }^{4}$ Institute of Primary Care, University of Zurich, Zurich, Switzerland
}

\section{Corresponding author}

Prof. Dr. med. Beat Knechtle

Medbase St. Gallen Am Vadianplatz

Vadianstrasse 26

9001 St. Gallen

Switzerland

Telefon

+41(0) 712269300

Telefax

+41 (0) 712269301

E-Mail

beat.knechtle@hispeed.ch 
43 The aim of the present study was to examine the relationship of force-velocity (F-v)

44 characteristics with age and race time in marathon runners. One hundred thirty five

45 male marathon runners (age $44.2 \pm 8.8$ years, height $176 \pm 6 \mathrm{~cm}$, body mass $24.7 \pm 2.6$

$46 \mathrm{~kg} \cdot \mathrm{m}^{-2}$ and personal record 4:02 $\left.\pm 0: 45 \mathrm{~h}: \mathrm{min}\right)$, separated into eight age groups $(<30$,

$4730-35, \ldots, 55-60,>60$ years), performed a F-v test on a cycle ergometer consisted of

48 four $7 \mathrm{~s}$ sprints. The older age groups had the lowest scores in maximal pedalling

49 velocity $\left(\mathrm{v}_{0} ; \mathrm{p}<0.001, \eta_{\mathrm{p}}{ }^{2}=0.244\right)$, relative $\left(\mathrm{rPmax} ; \mathrm{p}=0.001, \eta_{\mathrm{p}}{ }^{2}=0.176\right)$ and absolute

50 maximal power $\left(\operatorname{Pmax} ; \mathrm{p}=0.009, \eta_{\mathrm{p}}{ }^{2}=0.135\right)$, whereas no difference in maximal force

$51\left(\mathrm{~F}_{0} ; \mathrm{p}=0.558, \eta_{\mathrm{p}}{ }^{2}=0.044\right)$ was shown. Race time correlated moderately with $\mathrm{F}_{0}$

$52(\mathrm{r}=0.31, \mathrm{p}<0.001)$ and $\mathrm{Pmax}(\mathrm{r}=0.30, \mathrm{p}=0.001)$. The small magnitude of age-related

53 differences in anaerobic power among most age groups indicated that humans without

54 muscle strength/power training might maintain anaerobic power indices till their 60's.

55 Keywords: aging, anthropometry, cycle ergometer, muscle strength, speed 


\section{Introduction}

Exercise training has been routinely used in research modelling healthy ageing, especially considering the beneficial role of aerobic exercise for cardiovascular health (Hoffman \& Krouse, 2018; Montero \& Diaz-Canestro, 2016). Accordingly, several studies examined age-related differences in endurance athletes and showed that regular endurance training attenuates the decline in endurance with ageing (Knechtle \& Nikolaidis, 2018; Lepers \& Stapley, 2016; Tanaka \& Seals, 2008). On the contrary, little information exists with regards to the decline of parameters not related to endurance performance with ageing (e.g. anaerobic power, in endurance athletes). Marathon running is an endurance sport of increasing popularity (Cuk, Nikolaidis, \& Knechtle, 2019; Lepers \& Cattagni, 2012) and the study of marathon runners across lifespan could enhance our knowledge about whether engagement in this sport might also attenuate the decrease of anaerobic power. Marathon runners are characterized by a relatively low anaerobic power compared to athletes running shorter distances (Legaz-Arrese, Munguía-Izquierdo, Carranza-García, \& Torres-Dávila, 2011; Vuorimaa, 1996). For instance, in a 20s maximal anaerobic running test, marathon runners scored lower than sprinters and middle distance runners (Vuorimaa, 1996). Furthermore, in a comparison of distances from 100m to marathon, marathon runners had the lowest scores in the Wingate anaerobic test (WAnT) (Legaz-Arrese et al., 2011).

The ability of the human body to generate maximal power (Pmax) is linked to a host of performance outcomes and sporting success (Cross, Brughelli, Samozino, \& Morin, 2017). Maximal anaerobic power (Pmax) and force-velocity (F-v) relationships 
characterize limits of the neuromuscular system to produce power and their measurement has been a common topic in research for the last years (Cross et al., 2017). The F-v relationship, well established for an isolated muscle (Fenn \& Marsh, 1935), has been also documented for multi-articular movements such as cycling, where an increased braking force was associated with decreased pedalling velocity (Vandewalle, Pérès, Heller, \& Monod, 1985). The F-v test (Driss \& Vandewalle, 2013; Vandewalle et al., 1985) has been widely used in athletes such as judoists, boxers, taekwondo athletes (Busko, 2016), team handball (P.T. Nikolaidis et al., 2016), soccer (Nikolaïdis, 2012), tennis (Durand, Ripamonti, Beaune, \& Rahmani, 2010) and cyclists (P.T. Nikolaidis \& Papadopoulos, 2011), and non-athletes, such as elder women aged 50-70 years (Oesen, Bachl, \& Baron, 2015) and 66-82 years (Kostka et al., 1997). However, to the best of our knowledge, the F-v test has not been used previously in male marathon runners.

With regards to age-related changes in Pmax, it has been shown that this parameter assessed by a bipodal vertical jump test was reduced at the age of 75 years, both in absolute and relative units, to about $50 \%$ of the value measured at the age of 20 years (Grassi, Cerretelli, Narici, \& Marconi, 1991). Moreover, Grassi et al. (1991) suggested that changes after the age of 45 years should be attributed to a decrease in muscle mass. Pmax might be associated to performance in marathon running as it has been observed to be related to the cost of running in ultra-marathon runners (Giovanelli, Taboga, Rejc, \& Lazzer, 2017). Moreover, a decrease of Pmax after a marathon run has been shown previously (Petersen, Hansen, Aagaard, \& Madsen, 2007). 
The knowledge about Pmax and its components (i.e. F and v) would be of both theoretical and practical importance for gerontologists and physiologists interested in the mechanisms of ageing, and for coaches and fitness trainers working with marathon runners, respectively. The aim of the study was to assess the F-v profile of recreational marathon runners and examine the relationship of F-v characteristics with age, performance and anthropometry. Even if F-v characteristics were not related with marathon race time, they would aid endurance runners performing tasks with vigor in their daily life (Cattuzzo et al., 2016) or coping with increased muscular demands during a race (e.g. ascents or descents; Padulo et al., 2013). Considering previous research on the effect of aging on Pmax, assessed by vertical jump (Grassi et al., 1991), it was hypothesized that older marathon runners would exhibit lower Pmax than their younger counterparts. Furthermore, since a recent study did not find any relationship between F-v characteristics and race time in female marathon runners $(\mathrm{P}$. T. Nikolaidis, Rosemann, \& Knechtle, 2018), it was hypothesized that a similar trend would be observed in male marathon runners, too, where F-v characteristics would be expected to be relatively low compared to other physically active groups (e.g. master cyclists) (Chamari et al., 1995). 


\section{Study design}

127 To investigate the F-v characteristics in recreational marathon runners a cross-

128 sectional study design was applied, in which marathon runners were invited to

129 participate in a single-day experimental session. The study had been advertised through popular websites for endurance runners in the spring of 2017. Inclusion criteria were the documented finish in the Athens marathon 2016 - which was doublechecked in the results provided by the official website of the race (https://www.athensauthenticmarathon.gr/site/index.php/en/) - and the intention to participate in the Athens marathon 2017. Exclusion criterion was the existence of any 135 illness or injury inhibiting in participation to exercise testing. During September and October 2017, the participants visited the laboratory where they performed a F-v test on a cycle ergometer. Prior to exercise testing session, participants received detailed information about all procedures and became familiarized with the laboratory setting.

139 All subjects provided written informed consent and the study was conducted in 140 accordance with the Declaration of Helsinki. The protocol was approved by the local institutional review board.

\section{Participants}

144 One hundred thirty-five recreational marathon runners (age 44.2 \pm 8.8 years, height $145176 \pm 6 \mathrm{~cm}$, body mass $24.7 \pm 2.6 \mathrm{~kg} \cdot \mathrm{m}^{-2}$ and personal record 4:02 $\pm 0: 45 \mathrm{~h}: \mathrm{min}$, completed marathons in the past: median 3, interquartile range 2-6) mostly from the area of Athens volunteered to participate in this study. During the last month prior to testing, they were performing $4.3 \pm 1.3$ running sessions weekly corresponding to 
weekly running distance $52.7 \pm 21.1 \mathrm{~km}$. Participants were classified in eight 5-yearintervals age groups $(<30$ years, $n=7 ; 30-35$ years, $n=9 ; 35-40$ years, $n=25 ; 40-45$ years, $n=34 ; 45-50$ years, $n=31 ; 50-55$ years, $n=16 ; 55-60$ years, $n=6$; and $>60$ years, $\mathrm{n}=7$ ). In addition, they were grouped into quartiles based on their most recent race time: Q1 (2:27 - 3:29h:min, n=32), Q2 (3:30 - 3:59h:min, n=33), Q3 (4:00 4:27h:min; $\mathrm{n}=35)$ and Q4 (4:28 - 6:30h:min, $\mathrm{n}=33)$.

\section{Procedures}

Anthropometry. The height and body mass of participants were assessed in underwear clothing and barefoot using a portable stadiometer (SECA, Leicester, UK) to the nearest $0.001 \mathrm{~m}$ and an electronic weighing scale (HD-351; Tanita, Arlington Heights, IL, USA) to the nearest $0.1 \mathrm{~kg}$, accordingly. Skinfolds' thickness was measured by a calliper (Harpenden, West Sussex, UK) the nearest $0.2 \mathrm{~mm}$. Mid-thigh circumference was measured using an ergonomic circumference tape (SECA 201, Leicester, UK). Body fat percentage $(\mathrm{BF})$ was estimated from skinfolds using the equation $\mathrm{BF}=-41.32$ $+12.59 \times \log x$, where $x$ was the sum of ten skinfolds (cheek, wattle, triceps, subscapular, chest I, chest II, abdominal, suprailiac, front thigh and calf) (Parizkova, 1978). Fat-free mass (FFM) in $\mathrm{kg}$ was calculated as 'body mass - (body mass $\times$ BF / 100)'. Total thigh muscle cross-sectional area (CSA) was calculated as '(4.68 x midthigh circumference in $\mathrm{cm})-(2.09 \mathrm{x}$ anterior thigh skinfold in $\mathrm{mm})-80.99$ ' (Housh et al., 1995). Body mass index (BMI) was calculated as the quotient of body mass $(\mathrm{kg})$ to height squared $\left(\mathrm{m}^{2}\right)$.

\section{Force-velocity test. A task-specific warm-up - consisting of 9-min cycling of}


175

176

was employed to assess Pmax, expressed as $\mathrm{W}$ and as $\mathrm{W} / \mathrm{kg}$ (rPmax), theoretical maximal pedalling velocity $\left(\mathrm{v}_{0}\right)$ in revolutions per minute $(\mathrm{rpm})$ and force $\left(\mathrm{F}_{0}\right)$ in $\mathrm{N}$. In addition $\mathrm{v}_{0} / \mathrm{F}_{0}$ was calculated in $\mathrm{rpm} / \mathrm{N}$. This test employed various braking forces that elicit different pedalling velocities in order to derive Pmax (Driss \& Vandewalle, 2013). The participants performed four sprints, each one lasting seven seconds, against an incremental braking force $(3,4,5$ and $6 \mathrm{~kg}$ on a counterbalanced order) on a friction-loaded leg cycle ergometer (Ergomedics 874E, Monark, Sweden), interspersed by 5 -min recovery periods. The seat height of the ergometer was adjusted to allow for a slight bend in the knee (approximately $175^{\circ}$ ) and in accordance with the participant's satisfaction (Trecroci, Formenti, Rossi, Esposito, \& Alberti, 2017). Each sprint began with a flying start, i.e. as soon as pedalling velocity reached $50 \mathrm{rpm}$ (revolutions per minute), the weight basket of the cycle ergometer was released manually and the braking force was applied. For each participant an individual linear regression was determined between peak pedalling velocity and braking force for each of the four sprints. $\mathrm{F}_{0}$ and $\mathrm{v}_{0}$ corresponded to the intercepts with $\mathrm{F}$ and $\mathrm{v}$ axes in the F-v graph. Pmax was calculated as $\mathrm{Pmax}=0.25 \cdot \mathrm{F}_{0} \cdot \mathrm{v}_{0}$ (Vandewalle et al., 1985). Vandewalle et al. (1987) highlighted the almost perfect inversely linear relationship between the braking force and pedalling velocity in male and female athletes of various sport disciplines. All laboratory measurements were performed by the same qualified (MSc and PhD in Exercise Physiology and Exercise Testing, experience of exercise test administration to $>10,000$ athletes in the last 14 years) investigator to ensure a high reliability of measurements. 


\section{Statistical analyses}

200 Data were expressed as mean and standard deviation (SD). Normality was examined

201 using Kolmogorov-Smirnov test and visual inspection of normal quantile-quantile (Q-

202 Q) plots comparing probability distributions. One-way repeated measures analysis of

203 variance (ANOVA) and a subsequent Bonferroni post-hoc test (if there were

204 differences among groups) were used to examine the differences among age and

205 performance groups, separately. Partial eta square $\left(\eta_{\mathrm{p}}^{2}\right)$ was used to interpret effect

206 size (ES) of statistical differences for ANOVA and was classified as small $(0.010<$

$\left.207 \eta_{\mathrm{p}}{ }^{2} \leq 0.059\right)$, medium $\left(0.059<\eta_{\mathrm{p}}{ }^{2} \leq 0.138\right)$, and large $\left(\eta_{\mathrm{p}}{ }^{2}>0.138\right)$ (Cohen, 1988).

208 The relationship of F-v characteristics with age, performance and anthropometry was

209 examined using Pearson's product moment correlation coefficient $(r)$. The level of

210 significance was set at $\alpha=0.05$. Statistical analyses were performed using IBM SPSS

211 v.20.0 (SPSS, Chicago, IL, USA) and figures were created using GraphPad Prism v.

2127.0 (GraphPad Software, San Diego, USA). 


\section{Results}

\section{Profile of force-velocity characteristics}

With regards to the outcome measures of the F-v test, $v_{0}$ was $195 \pm 16$ rpm (ranging

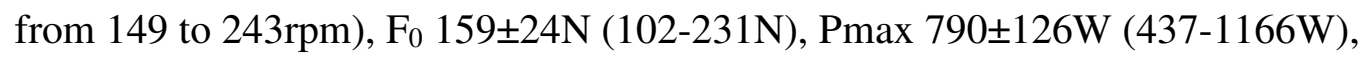
$\mathrm{rPmax} 10.3 \pm 1.5 \mathrm{~W} / \mathrm{kg}(6.2-14.7 \mathrm{~W} / \mathrm{kg})$ and $\mathrm{v}_{0} / \mathrm{F}_{0} 1.26 \pm 0.22 \mathrm{rpm} / \mathrm{N}(0.74-1.76 \mathrm{rpm} / \mathrm{N})$. The F-v relationship of all participants was presented in Figure 1.

\section{Differences in anthropometric and force-velocity characteristics among age groups}

A moderate-to-large main effect of age group was observed on body mass ( $\mathrm{p}=0.025$, $\left.\eta_{\mathrm{p}}^{2}=0.116\right), \mathrm{BMI}\left(\mathrm{p}=0.025, \eta_{\mathrm{p}}{ }^{2}=0.117\right), \mathrm{BF}\left(\mathrm{p}=0.034, \eta_{\mathrm{p}}{ }^{2}=0.110\right)$ and race record $\left(p=0.025, \eta_{p}^{2}=0.119\right)$, but not on body height $\left(p=0.261, \eta_{p}^{2}=0.066\right)$, FFM $(p=0.098$, $\left.\eta_{\mathrm{p}}{ }^{2}=0.089\right)$ and CSA $\left(\mathrm{p}=0.074, \eta_{\mathrm{p}}{ }^{2}=0.095\right)$ (Table 1). Athletes in age group 45-50 years were heavier and had a higher BMI than athletes in age group 35-40 years. A large main effect of age group on $\mathrm{v}_{0}\left(\mathrm{p}<0.001, \eta_{\mathrm{p}}{ }^{2}=0.244\right), \operatorname{rPmax}(\mathrm{p}=0.001$, $\left.\eta_{\mathrm{p}}{ }^{2}=0.176\right)$, and a moderate main effect on $\operatorname{Pmax}\left(\mathrm{p}=0.009, \eta_{\mathrm{p}}{ }^{2}=0.135\right)$ was observed with the older age groups showing the lowest scores, whereas no difference in $\mathrm{F}_{0}$ $\left(\mathrm{p}=0.558, \eta_{\mathrm{p}}{ }^{2}=0.044\right)$ was shown (Figure 2). Particularly, $>60$ group had lower $\mathrm{v}_{0}$ than $<30$ (-31 rpm), 30-35 (-25 rpm), 35-40 (-24 rpm) and 40-45 group (-23 rpm). Age group 55-60 had lower vo than $<30$ (-30 rpm), 35-40 (-23 rpm) and 40-45 group (-23 rpm), whereas age group 50-55 had lower $\mathrm{v}_{0}$ than $<30$ (-22 rpm) and 40-45 group (-15 rpm). In addition, >60 group had lower Pmax than 35-40 (-168 W), 40-45 (-181 W) and 45-50 group (-176 W), and lower rPmax than <30 (-2.4 W/kg), 30-35 (-2.4 $\mathrm{W} / \mathrm{kg}), 35-40(-2.7 \mathrm{~W} / \mathrm{kg})$ and 40-45 group (-2.0 W/kg). Age was inversely correlated 
with $\mathrm{v}_{0}(\mathrm{r}=-0.46, \mathrm{p}<0.001), \operatorname{Pmax}(\mathrm{r}=-0.26, \mathrm{p}=0.002), \mathrm{rPmax}(\mathrm{r}=-0.37, \mathrm{p}<0.001)$ and $\mathrm{v}_{0} / \mathrm{F}_{0}(\mathrm{r}=-0.20, \mathrm{p}=0.023)$, but not with $\mathrm{F}_{0}(\mathrm{r}=-0.04, \mathrm{p}=0.683)$.

\section{Differences in anthropometric and force-velocity characteristics among} performance groups

Performance group differed moderately-to-largely for age $\left(\mathrm{p}=0.007, \eta_{\mathrm{p}}{ }^{2}=0.089\right)$, body mass $\left(\mathrm{p}<0.001, \eta_{\mathrm{p}}{ }^{2}=0.150\right), \mathrm{BMI}\left(\mathrm{p}<0.001, \eta_{\mathrm{p}}{ }^{2}=0.225\right)$ and $\mathrm{BF}\left(\mathrm{p}<0.001, \eta_{\mathrm{p}}{ }^{2}=0.275\right)$, but not on body height $\left(p=0.920, \eta_{p}{ }^{2}=0.004\right)$, FFM $\left(p=0.068, \eta_{p}{ }^{2}=0.054\right)$ and CSA $\left(\mathrm{p}=0.060, \eta_{\mathrm{p}}{ }^{2}=0.055\right)$ (Table 2). The fastest performance group (Q1) was younger, lighter with a lower BMI and a lower BF than the slowest performance group (Q4).

Moreover, performance group differed moderately for on $\mathrm{F}_{0}\left(\mathrm{p}=0.013, \eta_{\mathrm{p}}{ }^{2}=0.080\right)$ and Pmax $\left(\mathrm{p}=0.035, \eta_{\mathrm{p}}{ }^{2}=0.065\right)$, with the slowest performance group (Q4) presenting higher scores than Q2 performance group, whereas no difference in $\mathrm{v}_{0}(\mathrm{p}=0.907$, $\left.\eta_{\mathrm{p}}{ }^{2}=0.004\right)$ and $\mathrm{rPmax}\left(\mathrm{p}=0.113, \eta_{\mathrm{p}}{ }^{2}=0.045\right)$ was shown (Figure 3$)$. Race time correlated moderately with $\mathrm{F}_{0}(\mathrm{r}=0.31, \mathrm{p}<0.001)$ and $\mathrm{Pmax}(\mathrm{r}=0.30, \mathrm{p}=0.001)$, but not with $\mathrm{v}_{0}(\mathrm{r}=-0.01, \mathrm{p}=0.952)$ and $\mathrm{rPmax}(\mathrm{r}=-0.01, \mathrm{p}=0.935)$.

\section{Relationship between force-velocity and anthropometric characteristics}

$\mathrm{V}_{0}$ correlated with FFM $(\mathrm{r}=0.24, \mathrm{p}=0.006), \mathrm{F}_{0}$ with FFM $(\mathrm{r}=0.44, \mathrm{p}<0.001)$ and CSA $(\mathrm{r}=0.34, \mathrm{p}<0.001)$, and Pmax with FFM $(\mathrm{r}=0.54, \mathrm{p}<0.001)$ and CSA $(\mathrm{r}=0.42$, $\mathrm{p}<0.001)$. 


\section{Discussion}

The main finding of the present study was that an inverse moderate correlation of the indices of muscle velocity $\left(\mathrm{v}_{0}\right)$ and relative power (rPmax) with age was observed, and the lowest scores was shown in the $>60$ age group. In addition, a moderate correlation of the indices of muscle force $\left(\mathrm{F}_{0}\right)$ and power $(\mathrm{Pmax})$ with race time was found (i.e. the higher the $\mathrm{F}_{0}$ and Pmax, the slower the race time) and the slowest group (Q4) presented higher scores than Q2. Furthermore, $\mathrm{F}_{0}$ and Pmax correlated with non-fat mass of the body (FFM).

\section{Profile of force-velocity characteristics}

270 The F-v characteristics of participants (Pmax 790W, $\mathrm{F}_{0} 159 \mathrm{~N}$ and $\mathrm{v}_{0} 195 \mathrm{rpm}$ ) could be evaluated as relatively low compared with previous studies using the F-v test in physically active men or master cyclists (Chamari, Ahmaidi, Fabre, Massé-Biron, \& Préfaut, 1995; Jaafar, 2017). For instance, physically active men's Pmax, Fo and v0 were $1115 \mathrm{~W}, 192 \mathrm{~N}$, and $228 \mathrm{rpm}$, respectively (Jaafar, 2017). In addition, master cyclists had Pmax 1089 W (Chamari et al., 1995). The profile of participants was in agreement with existing research reporting relatively low scores of anaerobic power in marathon runners compared to shorter distances' runners (Legaz-Arrese et al., 2011; Vuorimaa, 1996). Consequently, the research hypothesis of a relatively low

279 Pmax in marathon runners compared to athletes of other sports was confirmed, and 280 this was accompanied by both relatively low $\mathrm{v}_{0}$ and $\mathrm{F}_{0}$. 
The lower scores of rPmax and $\mathrm{v}_{0}$ in the oldest age group were in agreement with the negative correlations of age with these two F-v parameters. These findings confirmed previous studies showing a decline of anaerobic power with ageing (Bonnefoy, Kostka, Arsac, Berthouze, \& Lacour, 1998; Chamari et al., 1995). For instance, in a comparison between young ( 25 years) and master athletes ( 65 years) matched for body mass, body height and training, $\mathrm{P}_{\max }, \mathrm{F}_{0}$ and $\mathrm{v}_{0}$ were lower about $43 \%, 30 \%$ and $15 \%$, respectively, in the older athletes (Chamari et al., 1995). A study of younger (23 years) and elder men (71 years) showed a decline of $\mathrm{rP}_{\max }$ by $8 \%$ per decade and of maximal pedalling velocity by $4 \%$, and a moderate inverse relationship between $\mathrm{rP}_{\max }$ and age ( $\mathrm{r}=-0.33$ ) (Bonnefoy et al., 1998). A comparison between younger (31 years) and elder men (69 years) suggested a lower Pmax in the latter group by $27 \%$ (Marsh, Paterson, Govindasamy, \& Cunningham, 1999). A research on oarsmen and kayakers (30-67 years) reported a decline of peak power by 6-7\% per decade (Ladyga, Faff, Borkowski, \& Burkhard-Jagodzińska, 2009). Grassi and colleagues observed peak power in elder (75 years) lower by 50\% than young (20 years) (Grassi et al., 1991). In men 20-88 years, the decline in rPmax (10.3\% per decade) was higher than in aerobic capacity $(7.5 \%$ per decade) concluding that the age-associated decline in anaerobic power was steeper than that of aerobic power (Kostka, Drygas, Jegier, \& Zaniewicz, 2009). In highly trained master cyclists (35-64 years) rPmax declined at a rate of $8.1 \%$ per decade, whereas aerobic power did not change (Gent \& Norton, 2013). Therefore, the findings of the present study confirmed for the first time in male marathon runners the decline of rPmax with aging observed by the abovementioned studies in other sport groups. Furthermore, our findings - lowest scores of the oldest 
group in $\mathrm{rPmax}$ and $\mathrm{v}_{0}$, but not in $\mathrm{F}_{0}$ - suggested that the decline in $\mathrm{rPmax}$ should be attributed to the decline of $\mathrm{v}_{0}$ rather than to $\mathrm{F}_{0}$.

\section{Differences in anthropometric and force-velocity characteristics among}

performance groups

313 Race time correlated moderately with $\mathrm{F}_{0}$ and Pmax; indeed, the higher the anaerobic power, the slower the race time, which was in line with the highest scores of anaerobic power observed in the slowest (Q4) performance group. These findings confirmed that fast marathon runners were not characterized by a high anaerobic power (Legaz-Arrese et al., 2011; Vuorimaa, 1996), and indicated that an increased anaerobic power might be related with slow race time. Based on these findings, the training of marathon runners should not emphasize on the development of Pmax.

\section{Relationship between force-velocity and anthropometric characteristics}

The anaerobic power correlated with both FFM and CSA, which might explain why excess of FFM, even if this is 'active mass', is a load that marathon runners have to carry with them. Although an increased Pmax might improve the cost of running (Giovanelli et al., 2017), its association with increased FFM would lead to slower race time. The fastest group had the lowest BF, which was in agreement with research (Barandun et al., 2012; Knechtle et al., 2014) showing BF as predictor of race time in endurance running. Thus, it was concluded that the anthropometric characteristics of the marathon runners do not favour the development of high Pmax. 
Strength of this study was its novelty since it was the first to examine the F-v characteristics of male marathon runners and the findings could be used as norms and references for future studies. Furthermore, the sample size $(n=135)$ was one of the largest ever studied combining both laboratory and race data (e.g. $n=84$, male finishers in the Madrid marathon, Salinero et al., 2017; finishers in different marathon races, Tanda \& Knechtle, 2015) and this allowed the meaningful comparison among age and performance groups. In view of the increased participation in marathon races during the last decades (Lepers \& Cattagni, 2012), the findings were of great practical value for strength and conditioning coaches in the context of training and testing of their runners. Moreover, from a theoretical perspective the results might interest scientists focusing on aging such as exercise physiologists and gerontologists.

\section{Limitations}

A limitation of the present study was the ergometer and protocol that assessed anaerobic power. F-v test and WAnT did not provide similar estimates and their findings should not be used interchangeably (Jaafar, Rouis, Attiogbe, Vandewalle, \& Driss, 2016). In addition, anaerobic power was assessed on cycle ergometer and this choice might be criticized as non-sport specific (non-ecological) for marathon runners. Another limitation in the statistical analysis might be the comparison among different sized age groups. However, it should be highlighted that an uneven distribution of participants (most of them were in the 40-45 years age group and their number decreased as the age deviated from this range of age) into age groups was "ecologically" valid, since its pattern represented the distribution of finishers in marathon races. For instance, most finishers in the 'New York City Marathon', the largest marathon in the world, were in the 40-44 years age group (Nikolaidis \& 

anaerobic power into its two components, i.e. (braking) force and (pedalling) velocity.

359

360

361

362

363

364

365

366

367

370

371

372

373

374

375

376

377

378

379

380

381

Knechtle, 2018). On the other hand, the use of F-v test allowed the analysis of

\section{Conclusions}

In summary, male marathon runners were characterized by low levels of anaerobic power compared to non-endurance athletes. The observed age-related differences were smaller than those previously shown in non-athletes. The small magnitude of age-related differences in anaerobic power among most age groups indicated that humans without muscle strength/power training might maintain anaerobic power indices till their 60's. An excess of anaerobic power might be disadvantageous for marathon runners, likely due to its relationship with excess of fat-free mass. Considering the gap in the existing literature about the F-v characteristics of marathon runners, these findings added new information. 
383 The voluntarily participation of all marathon runners in the present study is greatly

384 appreciated.

\section{Conflict of Interest Statement}

387 The authors declare that the submitted work was not carried out in the presence of any 388 personal, professional or financial relationships that could potentially be construed as 389 a conflict of interest.

390

391 Author contribution

392 PN and BK contributed equally to this work. PN performed the experiments and

393 drafted the paper. BK helped in drafting the paper and edited the final version. 


\section{References}

Barandun, U., Knechtle, B., Knechtle, P., Klipstein, A., Rust, C. A., Rosemann, T., \& Lepers, R. (2012). Running speed during training and percent body fat predict race time in recreational male marathoners. Open Access Journal of Sports Medicine, 3, 51-58. doi: 10.2147/oajsm.s33284

Bonnefoy, M., Kostka, T., Arsac, L. M., Berthouze, S. E., \& Lacour, J. R. (1998). Peak anaerobic power in elderly men. European Journal of Applied Physiology and Occupational Physiology, 77(1-2), 182-188.

Busko, K. (2016). Power-velocity characteristics and jumping abilities in male combat athletes. Human Movement, 17(3), 181-184. doi: 10.1515/humo-20160019

Cattuzzo M. T., Dos Santos Henrique R., Re A. H., de Oliveira I. S., Melo B. M., de Sousa Moura M., et al. (2016). Motor competence and health related physical fitness in youth: A systematic review. Journal of Science and Medicine in Sport, 19, 123-129. 10.1016/j.jsams.2014.12.004

Chamari, K., Ahmaidi, S., Fabre, C., Massé-Biron, J., \& Préfaut, C. (1995). Anaerobic and aerobic peak power output and the force-velocity relationship in endurance-trained athletes: effects of aging. European Journal of Applied Physiology and Occupational Physiology, 71(2-3), 230-234.

Cohen, J. (1988). Statistical power analysis for the behavioral sciences (2nd ed.). Hillsdale, NJ: Lawrence Erlbaum Associates.

Cross, M. R., Brughelli, M., Samozino, P., \& Morin, J. B. (2017). Methods of powerforce-velocity profiling during sprint running: A narrative review. Sports Medicine, 47(7), 1255-1269. doi: 10.1007/s40279-016-0653-3 
Cuk, I., Nikolaidis, P.T., \& Knechtle, B. (2019). Sex differences in pacing during half-marathon and marathon race. Research in Sports Medicine, in print. doi: $10.1080 / 15438627.2019 .1593835$.

Driss, T., \& Vandewalle, H. (2013). The measurement of maximal (Anaerobic) power output on a cycle ergometer: A critical review. BioMed Research International, 2013, 589361. doi: 10.1155/2013/589361

Durand, S., Ripamonti, M., Beaune, B., \& Rahmani, A. (2010). Leg ability factors in tennis players. International Journal of Sports Medicine, 31(12), 882-886. doi: $10.1055 / \mathrm{s}-0030-1265202$

Fenn, W. O., \& Marsh, B. S. (1935). Muscular force at different speeds of shortening. Journal of Physiology, 85(3), 277-297.

Gent, D. N., \& Norton, K. (2013). Aging has greater impact on anaerobic versus aerobic power in trained masters athletes. Journal of Sports Sciences, 31(1), 97-103.

Giovanelli, N., Taboga, P., Rejc, E., \& Lazzer, S. (2017). Effects of strength, explosive and plyometric training on energy cost of running in ultra-endurance athletes. European Journal of Sport Science, 17(7), 805-813. doi:

$$
10.1080 / 17461391.2017 .1305454
$$

Grassi, B., Cerretelli, P., Narici, M. V., \& Marconi, C. (1991). Peak anaerobic power in master athletes. European Journal of Applied Physiology and Occupational Physiology, 62(6), 394-399.

Hoffman, M.D., \& Krouse, R. (2018). Ultra-obligatory running among ultramarathon runners. Research in Sports Medicine, 26(2), 211-221. doi: 
Housh, D. J., Housh, T. J., Weir, J. P., Weir, L. L., Johnson, G. O., \& Stout, J. R. (1995). Anthropometric estimation of thigh muscle cross-sectional area. Medicine \& Science in Sports \& Exercise, 27(5), 784-791.

Jaafar, H. (2017). Allometric scaling of power-force-velocity ergometry profiles in men. Annals of Human Biology, 44(7), 648-651. doi: $10.1080 / 03014460.2017 .1355012$

Jaafar, H., Rouis, M., Attiogbe, E., Vandewalle, H., \& Driss, T. (2016). A comparative study between the Wingate and force-velocity anaerobic cycling tests: Effect of physical fitness. International Journal of Sports Physiology and Performance, 11(1), 48-54. doi: 10.1123/ijspp.2015-0063

Knechtle, B., Barandun, U., Knechtle, P., Zingg, M. A., Rosemann, T., \& Rust, C. A. (2014). Prediction of half-marathon race time in recreational female and male runners. Springerplus, 3, 248. doi: 10.1186/2193-1801-3-248

Knechtle, B., \& Nikolaidis, P.T. (2018). Sex- and age-related differences in halfmarathon performance and competitiveness in the world's largest halfmarathon - the GöteborgsVarvet. Research in Sports Medicine, 26(1), 75-85. doi: 10.1080/15438627.2017.1393749

Kostka, T., Bonnefoy, M., Arsac, L. M., Berthouze, S. E., Belli, A., \& Lacour, J. R. (1997). Habitual physical activity and peak anaerobic power in elderly women. European Journal of Applied Physiology and Occupational Physiology, 76(1), 81-87.

Kostka, T., Drygas, W., Jegier, A., \& Zaniewicz, D. (2009). Aerobic and anaerobic power in relation to age and physical activity in 354 men aged 20-88 years. International Journal of Sports Medicine, 30(3), 225-230. 
Ładyga, M., Faff, J., Borkowski, L., \& Burkhard-Jagodzińska, K. (2009). Age-related changes in anaerobic power in the former highly trained Oarsmen and Kayakers. Biology of Sport, 26(2), 183-194.

Legaz-Arrese, A., Munguía-Izquierdo, D., Carranza-García, L. E., \& Torres-Dávila, C. G. (2011). Validity of the Wingate anaerobic test for the evaluation of elite runners. Journal of Strength and Conditioning Research, 25(3), 819-824. doi: 10.1519/JSC.0b013e3181c1fa71

Lepers, R., \& Cattagni, T. (2012). Do older athletes reach limits in their performance during marathon running? Age (Dordr), 34(3), 773-781. doi: 10.1007/s11357$011-9271-\mathrm{z}$

Lepers, R., \& Stapley, P. J. (2016). Master Athletes Are Extending the Limits of Human Endurance. Frontiers in Physiology, 7, 613. doi: 10.3389/fphys.2016.00613

Marsh, G. D., Paterson, D. H., Govindasamy, D., \& Cunningham, D. A. (1999). Anaerobic power of the arms and legs of young and older men. Experimental Physiology, 84(3), 589-597.

Montero, D., \& Diaz-Canestro, C. (2016). Endurance training and maximal oxygen consumption with ageing: Role of maximal cardiac output and oxygen extraction. European Journal of Preventive Cardiology, 23(7), 733-743. doi: $10.1177 / 2047487315617118$

Nikolaïdis, P. T. (2012). Age-related differences in force-velocity characteristics in youth soccer. Kinesiology, 44(2), 130-138.

Nikolaidis, P. T., \& Knechtle, B. (2018). Pacing in age group marathoners in the “New York City Marathon”. Research in Sports Medicine, 26(1), 86-99. doi: $10.1080 / 15438627.2017 .1393752$ 
Nikolaidis, P. T., \& Papadopoulos, V. E. (2011). Cardiorespiratory power and forcevelocity characteristics in road cycling: the effect of aging and underlying physiological mechanisms. Medicina Sportiva, 15(2), 68-74.

Nikolaidis, P. T., Rosemann, T., \& Knechtle, B. (2018). Force-velocity characteristics, muscle strength, and flexibility in female recreational marathon runners. Frontiers in Physiology, 9, 1563. doi: 10.3389/fphys.2018.01563

Nikolaidis, P. T., Torres-Luque, G., Chtourou, H., Clemente-Suarez, V. J., RamírezVélez, R., \& Heller, J. (2016). Comparison between jumping vs. cycling tests of short-term power in elite male handball players: The effect of age. Movement and Sports Sciences - Science et Motricite, 29(91), 93-101. doi: $10.1051 / \mathrm{sm} / 2015046$

Oesen, S., Bachl, N., \& Baron, R. (2015). Assessment of aerobic and anaerobic power as reference values in older aged women. Medicina dello Sport, 68(4), 541554.

Padulo J., Powell D., Milia R., \& Ardigo L. P. (2013). A paradigm of uphill running. PLoS One, 8:e69006. 10.1371/journal.pone.0069006

Parizkova, J. (1978). Lean body mass and depot fat during autogenesis in humans. In J. Parizkova \& V. Rogozkin (Eds.), Nutrition, Physical Fitness and Health: International Series on Sport Sciences. Baltimore: University Park Press.

Petersen, K., Hansen, C. B., Aagaard, P., \& Madsen, K. (2007). Muscle mechanical characteristics in fatigue and recovery from a marathon race in highly trained runners. European Journal of Applied Physiology, 101(3), 385-396. doi: 10.1007/s00421-007-0504-X 
Salinero, J. J., Soriano, M. L., Lara, B., Gallo-Salazar, C., Areces, F., Ruiz-Vicente, D., . . Del Coso, J. (2017). Predicting race time in male amateur marathon runners. Journal of Sports Medicine and Physical Fitness, 57(9), 1169-1177. doi: $10.23736 / \mathrm{s} 0022-4707.16 .06503-8$

Tanaka, H., \& Seals, D. R. (2008). Endurance exercise performance in Masters athletes: age-associated changes and underlying physiological mechanisms. Journal of Physiology, 586(1), 55-63. doi: 10.1113/jphysiol.2007.141879

Tanda, G., \& Knechtle, B. (2015). Effects of training and anthropometric factors on marathon and $100 \mathrm{~km}$ ultramarathon race performance. Open Access Journal of Sports Medicine, 6, 129-136. doi: 10.2147/oajsm.s80637

Trecroci, A., Formenti, D., Rossi, A., Esposito, F., \& Alberti, G. (2017). Acute effects of kinesio taping on a 6 s maximal cycling sprint performance. Research in Sports Medicine, 25(1), 48-57. doi: 10.1080/15438627.2016.1258644

Vandewalle, H., Pérès, G., Heller, J., \& Monod, H. (1985). All out anaerobic capacity tests on cycle ergometers - A comparative study on men and women. European Journal of Applied Physiology and Occupational Physiology, 54(2), 222-229. doi: 10.1007/BF02335934

Vandewalle, H., Peres, G., Heller, J., Panel, J., \& Monod, H. (1987). Force-velocity relationship and maximal power on a cycle ergometer - Correlation with the height of a vertical jump. European Journal of Applied Physiology and Occupational Physiology, 56(6), 650-656. doi: 10.1007/BF00424805

Vuorimaa, T. (1996). Comparison of three maximal anaerobic running test protocols in marathon runners, middle-distance runners and sprinters. International Journal of Sports Medicine, 17(SUPPL. 2), S109-S113. 


\section{Legends of figures}

542

Figure 1 Force-velocity relationship of all participants represented by pedalling velocity against braking force 3, 4, 5 and $6 \mathrm{~kg}$. confidence intervals of linear regression.

Differences in theoretical maximal velocity $\left(\mathrm{v}_{0}\right)$, force $\left(\mathrm{F}_{0}\right)$, maximal power in absolute (Pmax) and relative values ( $r P m a x)$, and $\mathrm{v}_{0} / \mathrm{F}_{0}$ among age groups.

* Different from $<30$ age group at $\mathrm{p}<0.05$.

Differences in theoretical maximal velocity $\left(\mathrm{v}_{0}\right)$, force $\left(\mathrm{F}_{0}\right)$, maximal power in absolute (Pmax) and relative values ( $\mathrm{rPmax}$ ), and $\mathrm{v}_{0} / \mathrm{F}_{0}$ among performance groups. race time with Q1 the fastest and Q4 the slowest. 


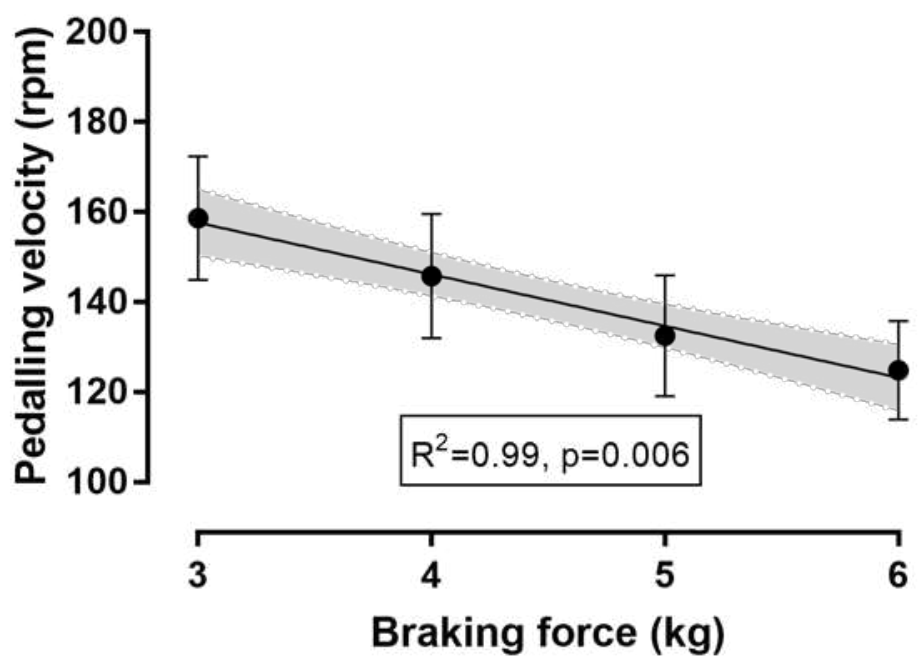

559

Figure 1

561 

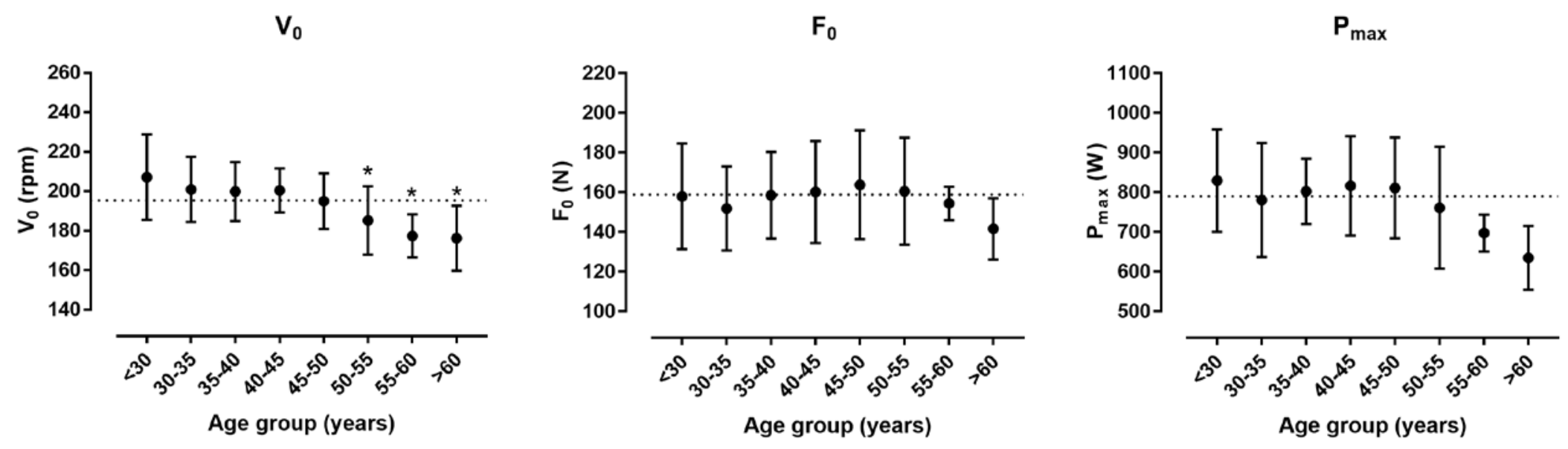

$\mathrm{rP}_{\text {max }}$

$\mathrm{V}_{0} / \mathrm{F}_{0}$
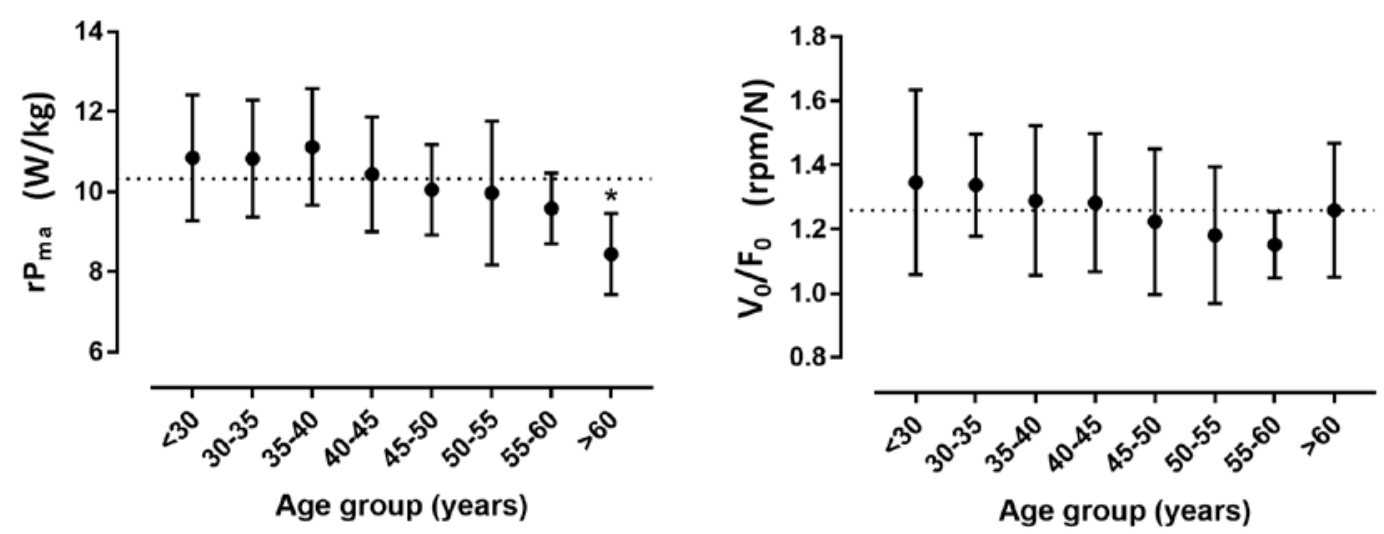

Figure 2 

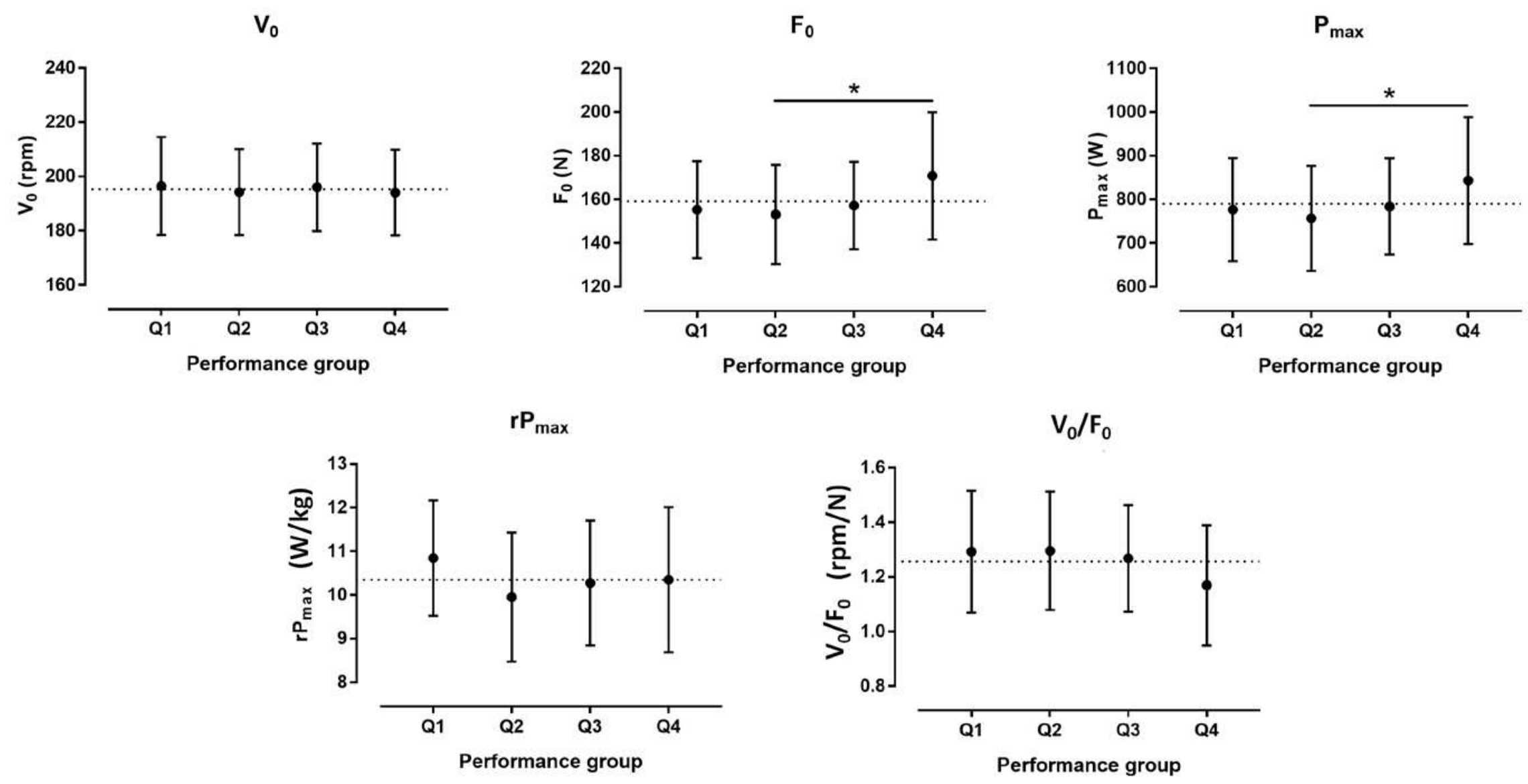

Figure 3 
Table 1. Comparison among age groups.

\begin{tabular}{|c|c|c|c|c|c|c|c|c|}
\hline & \multicolumn{8}{|c|}{ Age groups } \\
\hline & $<30$ & 30-35 & $35-40$ & $40-45$ & $45-50$ & $50-55$ & $55-60$ & $>60$ \\
\hline $\mathrm{n}$ & 7 & 9 & 25 & 34 & 31 & 16 & 6 & 7 \\
\hline Age (years) & $26.7 \pm 2.6$ & $32.2 \pm 1.4$ & $37.9 \pm 1.6$ & $42.4 \pm 1.4$ & $47.2 \pm 1.5$ & $52.0 \pm 1.2$ & $58.2 \pm 1.7$ & $64.8 \pm 4.0$ \\
\hline Height $(\mathrm{cm})$ & $177 \pm 5$ & $176 \pm 5$ & $176 \pm 6$ & $178 \pm 6$ & $177 \pm 5$ & $176 \pm 6$ & $174 \pm 9$ & $172 \pm 6$ \\
\hline Body mass $(\mathrm{kg})$ & $76.6 \pm 7.1$ & $72.2 \pm 9.5$ & $72.8 \pm 7.0$ & $78.5 \pm 9.1$ & $81.0 \pm 11.2$ & $76.3 \pm 8.1$ & $73.1 \pm 5.4$ & $75.5 \pm 8.5$ \\
\hline BMI $\left(\mathrm{kg} / \mathrm{m}^{2}\right)$ & $24.5 \pm 1.6$ & $23.4 \pm 2.4$ & $23.6 \pm 1.9$ & $24.7 \pm 2.3$ & $26.0 \pm 3.4$ & $24.6 \pm 2.0$ & $24.1 \pm 0.9$ & $25.7 \pm 3.4$ \\
\hline $\mathrm{BF}(\%)$ & $15.7 \pm 4.7$ & $14.7 \pm 3.6$ & $16.3 \pm 4.3$ & $18.1 \pm 3.2$ & $19.1 \pm 4.6$ & $18.2 \pm .2$ & $16.8 \pm 4.5$ & $19.0 \pm 4.2$ \\
\hline FFM (kg) & $64.4 \pm 4.2$ & $61.4 \pm 6.4$ & $60.7 \pm 4.1$ & $64.2 \pm 6.5$ & $65.2 \pm 6.9$ & $62.3 \pm 6.3$ & $60.7 \pm 4.5$ & $60.9 \pm 4.2$ \\
\hline $\operatorname{CSA}\left(\mathrm{cm}^{2}\right)$ & $147 \pm 5$ & $144 \pm 17$ & $138 \pm 15$ & $146 \pm 13$ & $143 \pm 14$ & $141 \pm 13$ & $132 \pm 12$ & $132 \pm 11$ \\
\hline
\end{tabular}

568 BMI=body mass index, $\mathrm{BF}=$ body fat percentage, FFM=fat-free mass, CSA=thigh muscle cross-sectional area. ${ }^{*} \mathrm{p}<0.01,{ }^{\dagger} \mathrm{p}<0.001$ 
Table 2. Comparison among performance groups (quartiles).

\section{Performance groups}

\begin{tabular}{lcccc}
\hline & Q1 $(\mathbf{n}=32)$ & Q2 $(\mathbf{n}=33)$ & Q3 $(\mathbf{n}=35)$ & Q4 (n=33) \\
\hline Age (years) & $40.9 \pm 9.5^{* \mathrm{Q} 4}$ & $43.7 \pm 9.6$ & $43.9 \pm 7.9$ & $48.3 \pm 6.9^{* \mathrm{Q} 1}$ \\
Height $(\mathrm{cm})$ & $176 \pm 6$ & $177 \pm 6$ & $177 \pm 6$ & $176 \pm 6$ \\
Body mass $(\mathrm{kg})$ & $71.7 \pm 8.2^{\dagger \mathrm{Q} 4}$ & $76.4 \pm 8.9$ & $76.6 \pm 7.2$ & $81.9 \pm 10.2^{\dagger \mathrm{Q} 1}$ \\
BMI $\left(\mathrm{kg} / \mathrm{m}^{2}\right)$ & $23.0 \pm 1.9^{\dagger \mathrm{Q} 4}$ & $24.5 \pm 2.6^{* \mathrm{Q} 4}$ & $24.5 \pm 1.6^{* \mathrm{Q} 4}$ & $26.5 \pm 2.9^{\dagger \mathrm{Q} 1, * \mathrm{Q} 2, * \mathrm{Q} 3}$ \\
BF $(\%)$ & $14.1 \pm 3.9^{\dagger \mathrm{Q} 2, \dagger \mathrm{Q} 3, \dagger \mathrm{Q} 4}$ & $17.9 \pm 3.6^{\dagger \mathrm{Q} 1}$ & $18.0 \pm 2.9^{\dagger \mathrm{Q} 1}$ & $20.1 \pm 3.5^{\dagger \mathrm{Q} 1}$ \\
FFM $(\mathrm{kg})$ & $61.3 \pm 5.7$ & $62.6 \pm 6.3$ & $62.7 \pm 5.4$ & $65.2 \pm 6.4$ \\
CSA $\left(\mathrm{cm}^{2}\right)$ & $136 \pm 14$ & $142 \pm 12$ & $143 \pm 13$ & $145 \pm 16$
\end{tabular}

571 Q1, Q2, Q3 and Q4=quartiles of race time, BMI=body mass index, BF=body fat

572 percentage, $\mathrm{FFM}=$ fat-free mass, $\mathrm{CSA}=$ thigh muscle cross-sectional area. $* \mathrm{p}<0.01$, $573{ }^{\dagger} \mathrm{p}<0.001$

574

575 